\title{
2D ACCELERATOR DESIGN FOR SITEX NEGATIVE ION SOURCE*
}

J. H. Whealton, R. J. Raridon, R. W. McGaffey,

D. H. McCollough, W. L. Stirling, and W. K. Dagenhart

Oak Ridge National Laboratory

Oak Ridge, Tennessee 37830

\section{ABSTRACT}

Solving the Poisson-Vlasov equations

COHF $-831180--8$

$\nabla^{2} \phi=\int f d \mathbf{v}-e^{-\phi}$

DE84. 003301

$$
(\mathbf{v} \times \mathbf{B}+\nabla \phi) \cdot \nabla_{v} f+\mathbf{v} \cdot \nabla f=0
$$

where the magnetic field, $B$, is assumed constant, we optimize the optical system of a SITEX negative ion source in $\infty$ slot geometry. Algorithms designed to solve the above equations were modified to include the curved emitter boundary data appropriate to a negative ion source. Other configurations relevant to negative ion sources are examined.

BODY

First we will consider the SITEX negative ion source (Ref. 2) which is shown in Fig. 1. On the left is a curved converter surface where ions are ejected out via a plasma sheath due to the adjacent source plasma at an energy of approximately 150 volts. There is a magnetic field perpendicular to the paper of approximately 1300 gauss. Upon entering the accelerator, the negative ioris leave the positive source plasma ions behind and accelerate to the desired potential. The optics is determined by the ion initial ejection velocity, the shape of the plasma extraction double sheath, and the applied electrostatic fields as manipulated by the geometry of the electrode shape. The plasma model abovs assumes that the excess source plasma positive ion density is representable by a Boltzmann distribution; otherwise it is assumed to exactly cancel out the electron density. This matter should really be modeled by solving three Vlasov equations coupling into a Poisson equation instead of one Vlasov equation and a Boltamann equation coupling into a Poisson equation. The modeling of the source plasma is important: for example, if the Boltzmann term in Eq. (2) were not present then we would get a result like Fig. 2 instead of Fig. 1 which is a solution to Eq. (1) and (2) as they stand for an optimum geometry at optimum perveance. The RMS beam divergence is $0.28^{\circ}$ due entirely to eleztrcztitic aberrations. The variation of divergence with beam ‥: : :. $::$ Ferveance is shown in Fig. 3; a situation of lower than c=氵inu... Derveance is shown in Fig. 4 and a case of higher than :-inum zerveance is shown in Fig. 5. The phase space emittance as $E \quad \cdots \cdots \cdots n$ of acceleration potential is shown in Fig. 6 . The 
accuracy of construction of this negative ion accelerator is hinted at by the sharp variations shown in Fig. 3 and is elucidated in Fig. 7. Fig. 7 shows how a variation in the focal point in either the beam direction $f(x)$, or the transverse direction $f(y)$, effects the RMS beam divergence.

Another negative ion source (Ref. 3) incorporates a long region (thousands of Debye lengths long) when the negative ions are transported through a plasma before being accelerated. The plasma model is very important in modeling this configuration as illustrated in Fig. 8 for five different plasma temperatures. We are proposing to study this device using a triple vlasov model.

Several accelerators (Ref. 4) using a Soviet source were examined.

A study is underway to determine if there are aberrations in the LBL-TFF accelerator (Ref. 5) shown in Fig. 9 for some nonoptimized cases. Shown in Fig. 10 is a preliminary finding of one accelerator gap from which the aberrations can be deduced.

\section{REFERENCES}

1. J. H. Whealton, R. W. McGaffey, and E. F. Jaeger, Appl. Phys. Lett. 36, 91 (1980); J. H. Whealton, Jour. Comput. Phys. 40491 (1981); J. H. Whealton, Nuc. Instrum. Meth. 189, 55 (1981).

2. W. L. Stirling, proceedings this conference.

3. Lietzke/inlers/Leung, proceedings this conference.

4. Smith/Allison/Sherman, proceedings this conference.

5. 0 . Anderson, proceedings this conference.

* Research sponsored by Union Carbide Corporation under contract No. W-7405-eng-26 for the U.S. Department of Energy, DOE.

\section{DISCLAIMER}

This report was prepared as an account of work sponsored by an agency of the United States Government. Neither the United States Government nor any agency thereof, nor any of their employees, makes any warranty, express or implied, or assumes any legal liability or responsibility for the accuracy, completeness, or usefulness of any information, spparatus, product, or process disclosed, or represents that its use would not infringe privately owned rights. Reference herein to any specific commercial product, process, or service by trade name, trademark, manufacturer, or otherwise does not necessarily constitute or imply its endorsement, recommendation, or favoring by the United States Government or any agency thereof. The views and opinions of authors expressed herein do not necessarily state or rellect those of the United States Government or any agency thereof. 

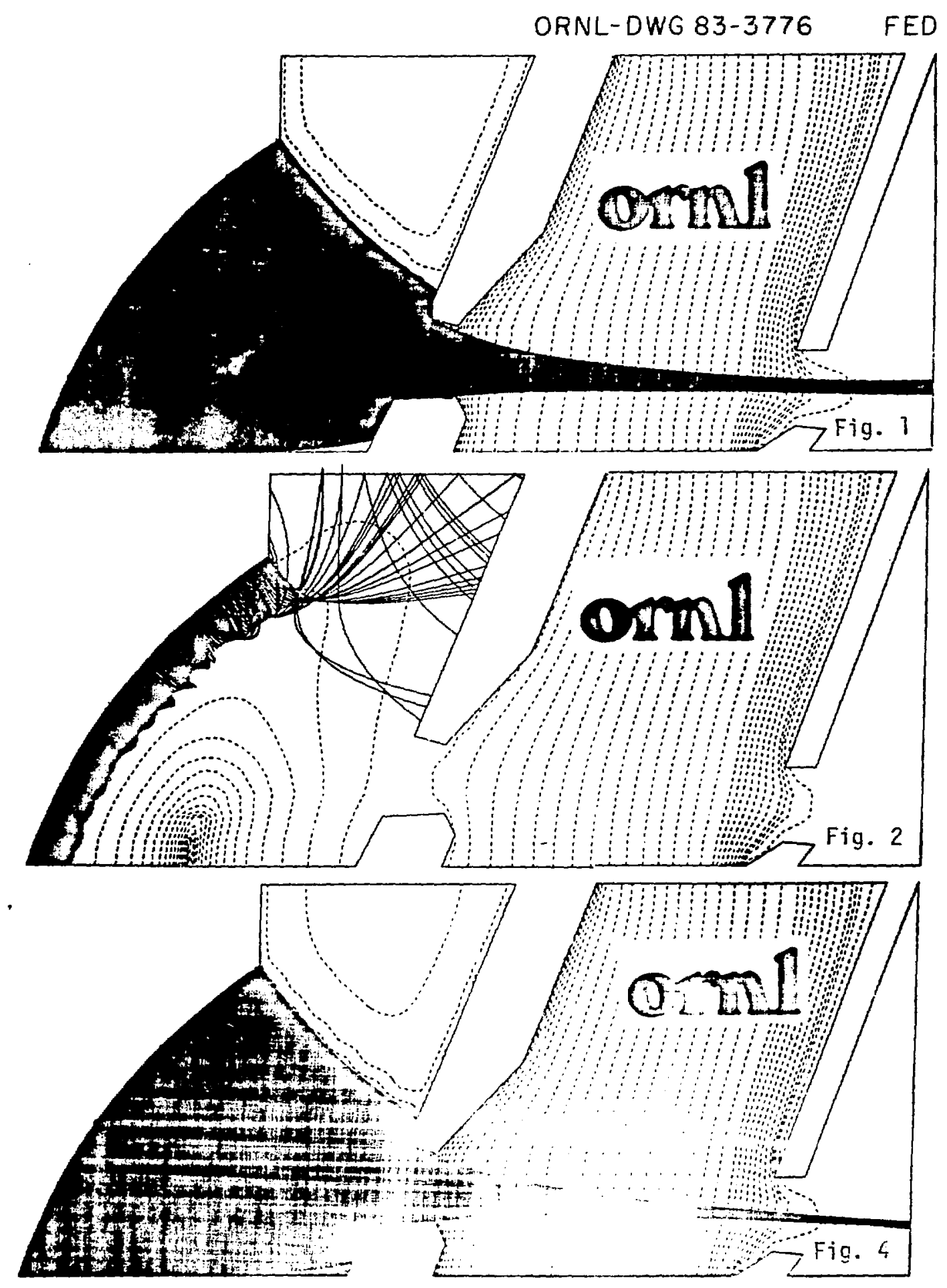
Figure 3

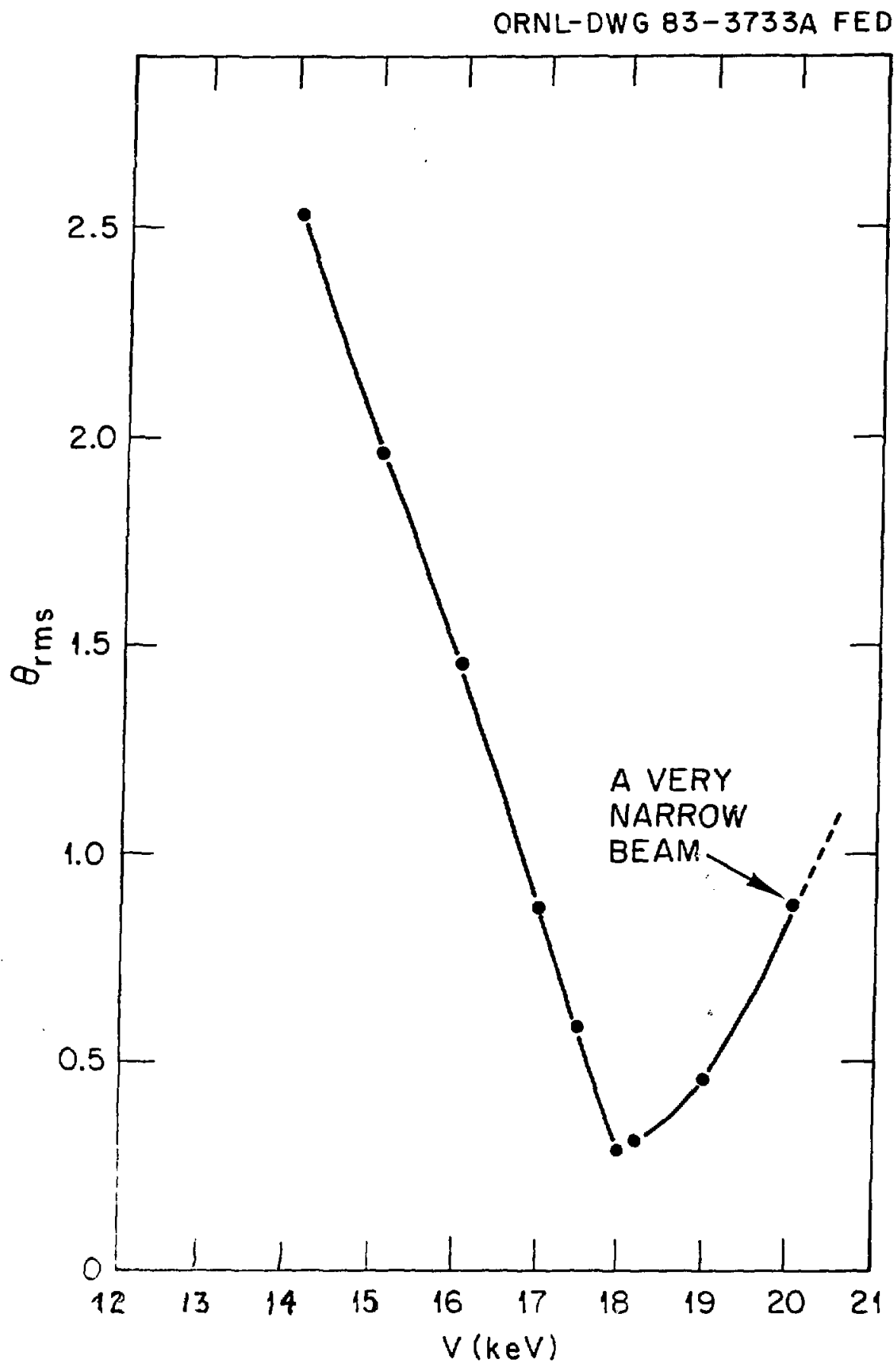




\section{Figure 5}

ORNL-DWG 83-3777 FED

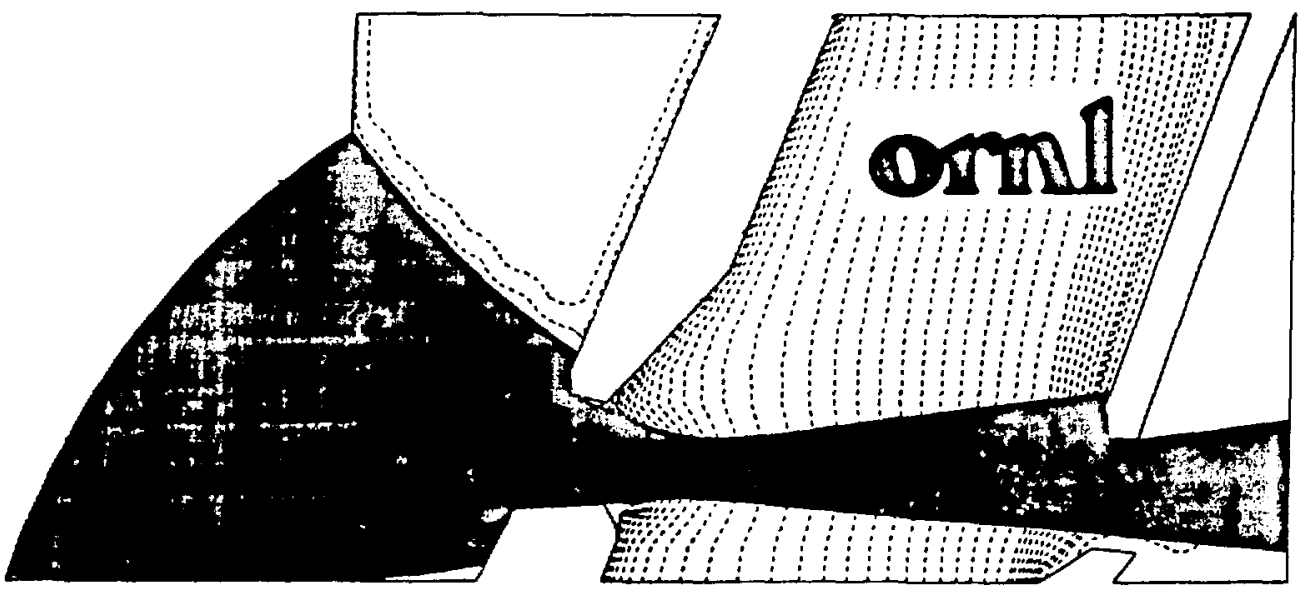

Figure 6

ORNL-DWG 83-3778 FED

NUMBERS ARE ACCELERATING POTENTIALS
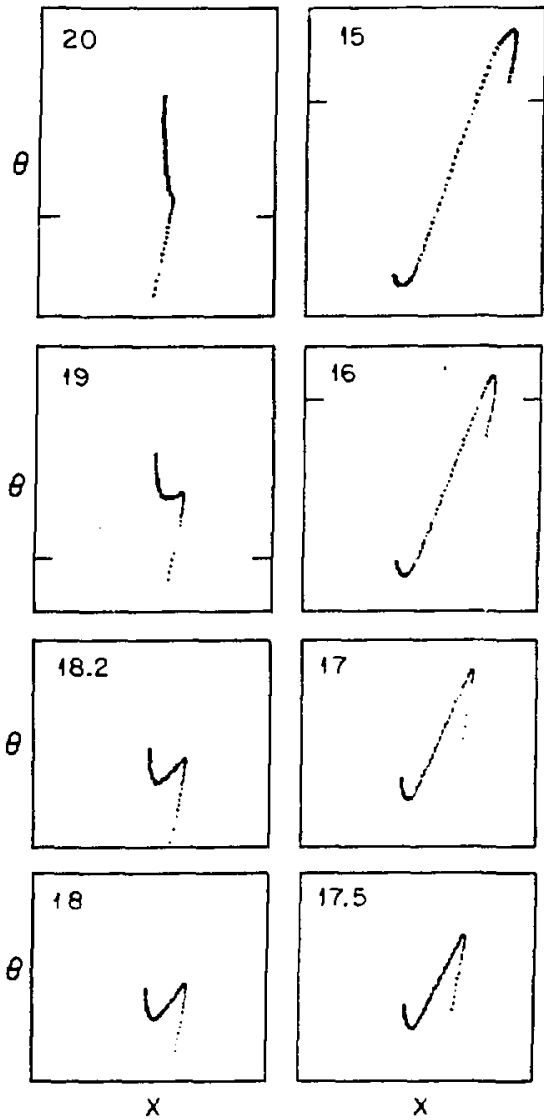

Figure 7

VARIATION OF BEAM DIVERGENCE WITH FOCAL POINT POSITION

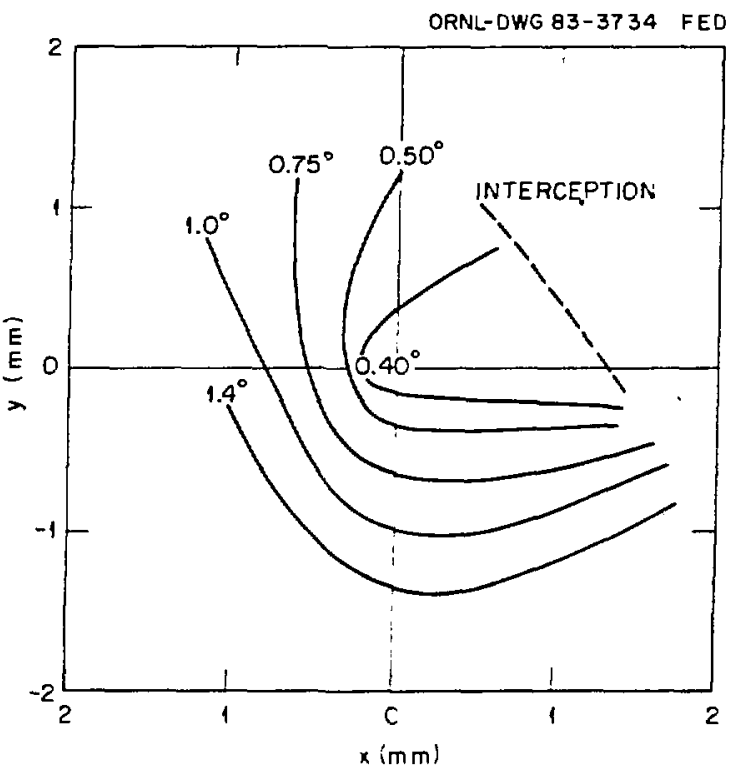


Figure 8

ORNL-DWG 83-3779 FED
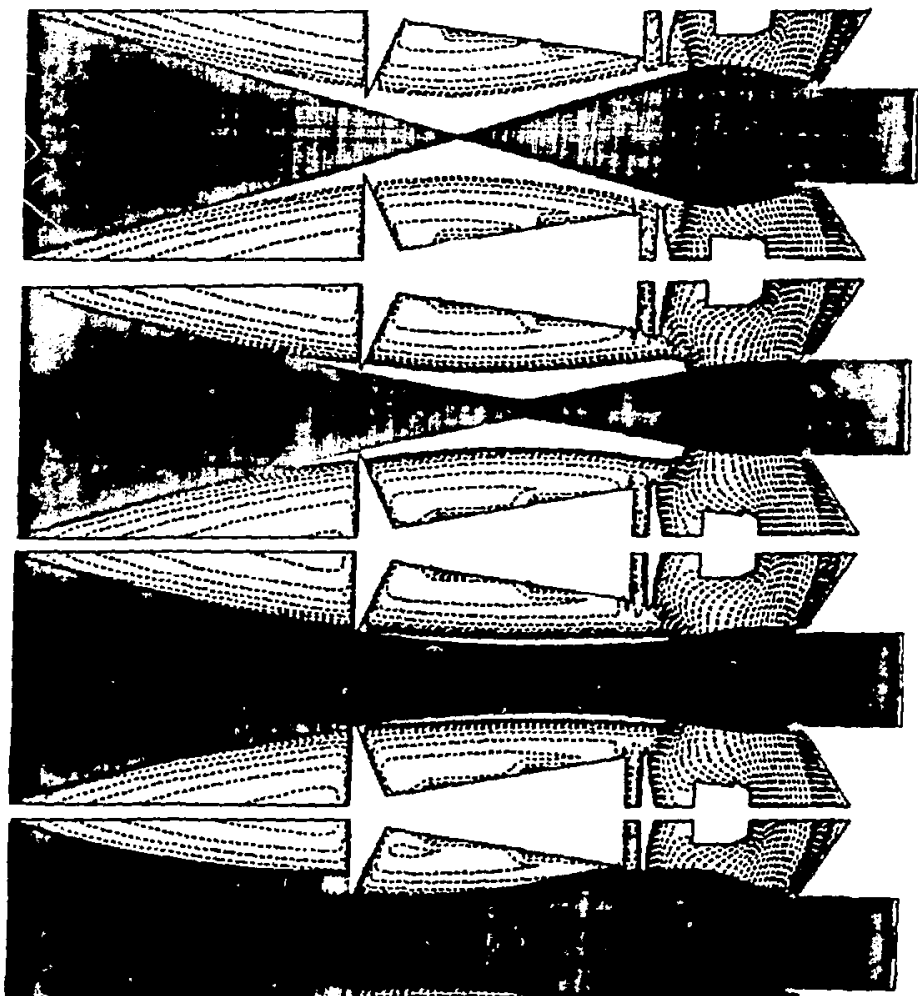

(4)

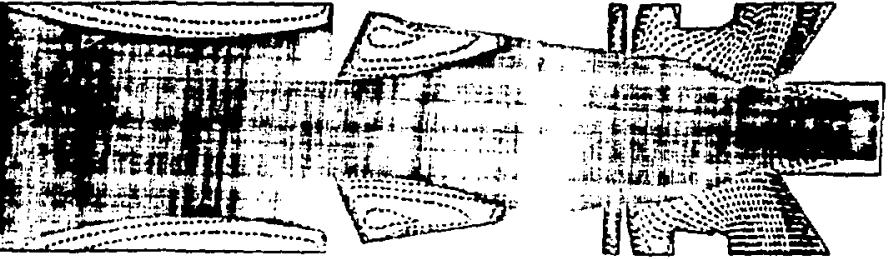


Figure 9

LBL'S TFF ACCELERATOR

ORNL-DWG 83-3781 FED
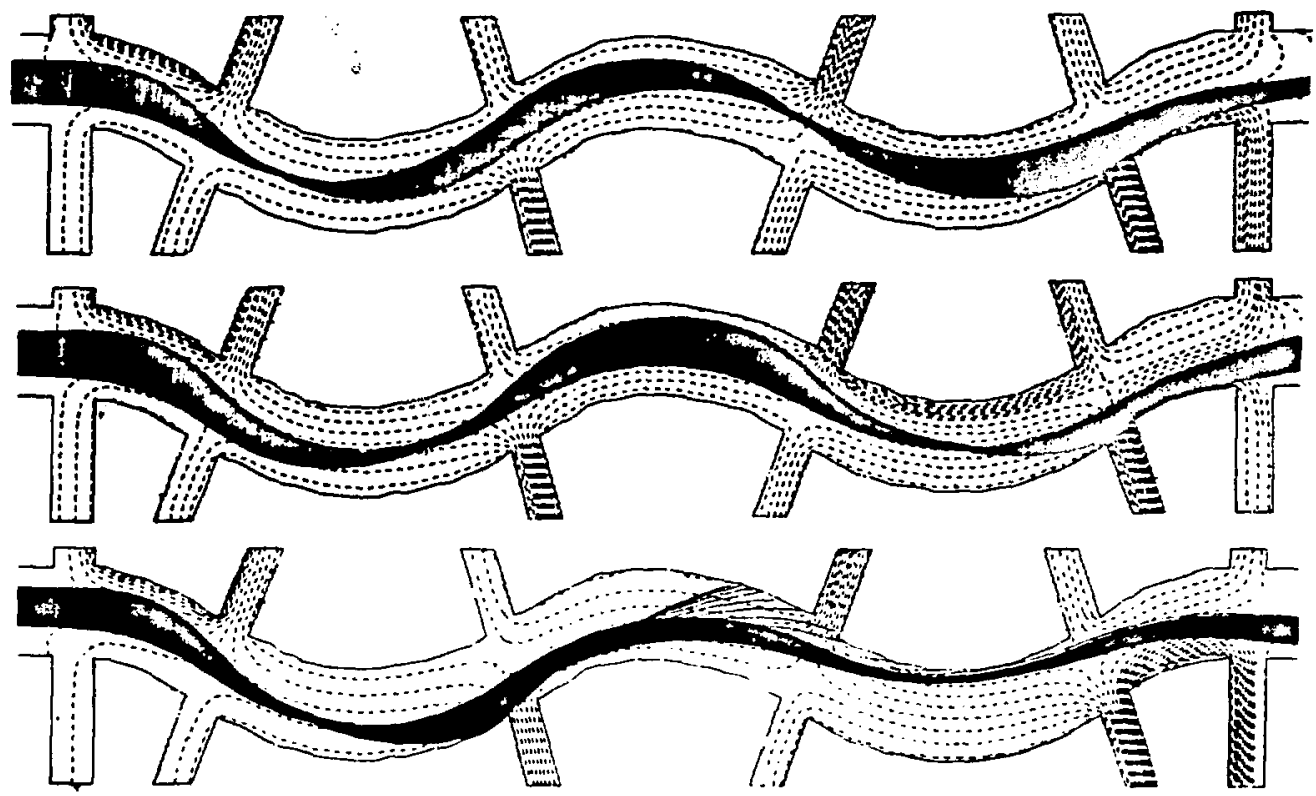


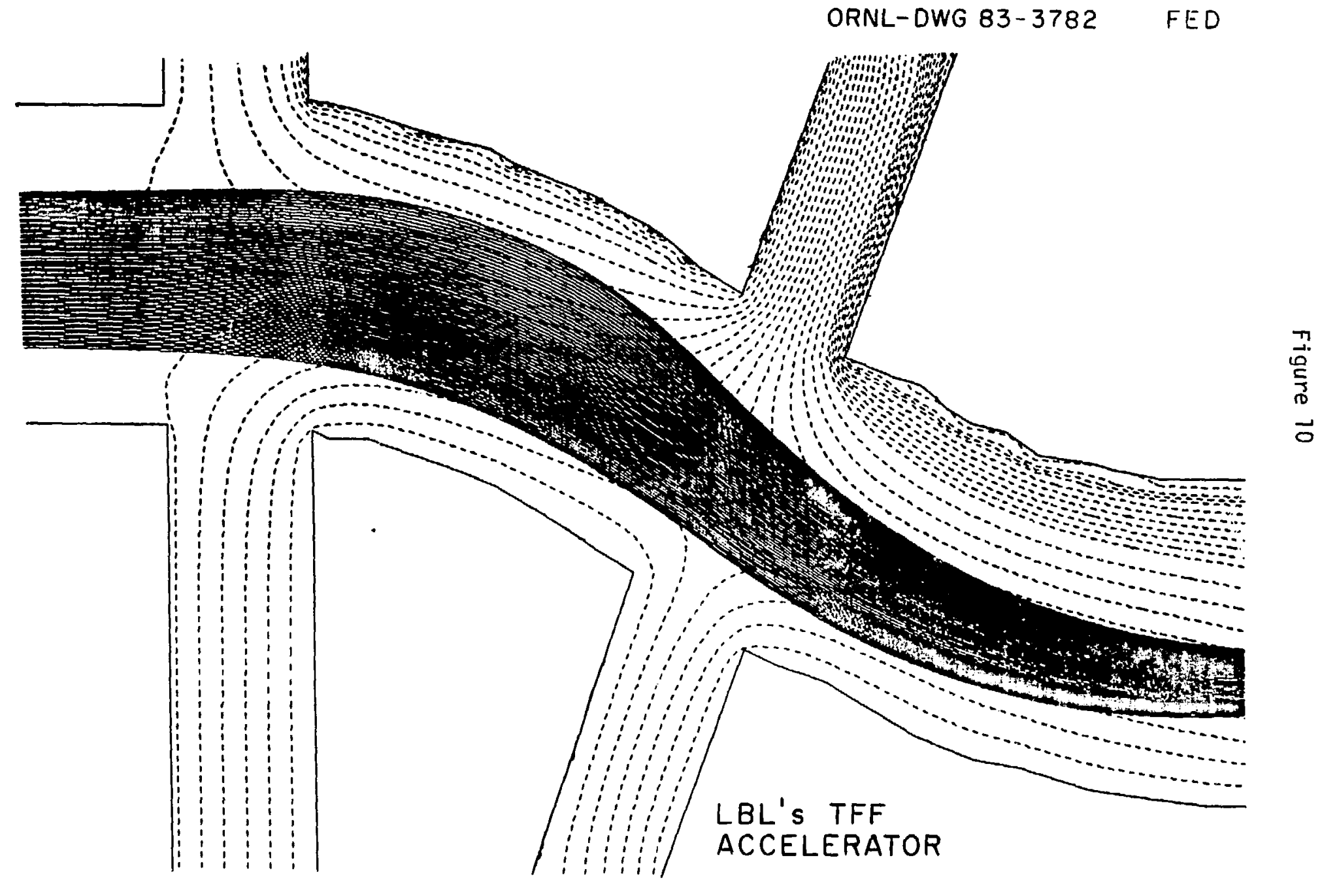

